\title{
An Outbreak of Systemic Granulomatous Disease in Cows with High Milk Yields
}

\author{
Ayako IIZUKA ${ }^{1)}$, Makoto HARITANI ${ }^{2) *}$, Mitsuo $\mathrm{SHIONO}^{1)}$, Mitsuo $\mathrm{SATO}^{3)}$, Osamu FUKUDA ${ }^{3)}$, Atsuko HAGIWARA ${ }^{3)}$, \\ Shigeru MIYAZAKI ${ }^{2}$, Nobuhiko TANIMURA ${ }^{2}$, Kumiko KIMURA ${ }^{2)}$, Kyoko NAKAZAWA ${ }^{2)}$, \\ Masaru KOBAYASHI ${ }^{2)}$, Takashi TAKAHASHI ${ }^{1)}$, Toshiya SAITO ${ }^{1)}$ and Katsuhiko FUKAI ${ }^{1)}$ \\ ${ }^{1)}$ Tochigi Prefectural Ken-oh Livestock Hygiene Service Center, Utsunomiya, Tochigi 321-0905, ${ }^{2)}$ National Institute of Animal Health, \\ Tsukuba, Ibaraki 305-0856 and ${ }^{3)}$ Tochigi Prefectural Ken-hoku Livestock Hygiene Service Center, Nasu, Tochigi 329-2713, Japan
}

(Received 8 November 2004/Accepted 29 March 2005)

ABSTRACT. Seven of 92 lactating Holstein cows on a dairy farm developed urticaria with alopecia and decreased milk production, and three of the seven died over the course of 7 to 18 days. Pathologic examination of the three cows, including the two dead and one euthanized cow, revealed that the skin, liver, spleen, kidneys, heart, salivary glands, pancreas, adrenal glands, mammary glands, lymph nodes, and trigeminal ganglia had lymphocytic to lymphogranulomatous inflammation. Inflammation predominated by lymphocytic infiltration was prominent in the heart, pancreas, mammary glands, adrenal gland, and trigeminal ganglia. Severe granulomatous inflammation with multinucleated giant cells was present in the spleen and kidneys. These lesions and their distributions were most similar to those seen in suspected cases of citrus pulp toxicosis and hairy vetch toxicosis. The outbreak of this disease resolved with the elimination of Citrus pulp from the feed. Immunohistochemical detection of lymphocytes and macrophage markers confirmed dramatic hyperplasia of CD3positive $\mathrm{T}$ lymphocytes in these lesions. This strongly suggested that a type 4 hypersensitivity reaction played a role in the development of the lesions.

KEY WORDS: alopecia, dairy cow, lymphogranuloma, type 4 hypersensitivity reaction, urticaria

Outbreaks of a disease in cows that was pathologically diagnosed as generalized granulomatosis, and in which the main clinical sign was dermatitis, have been reported to be caused by poisoning originating from the feeding of a legume called hairy vetch, 1, 1-diureidoisobutane (DUIB) (used as a protein feed substitute), citrinin (a mycotoxin found in feed), or citrus pulp [2-7,9,11]. In these diseases, lymphocytic to lymphogranulomatous inflammation in multiple organs was observed on histopathological examination. Furthermore, the histopathologic features suggested that a type 4 hypersensitivity reaction might play a role in the initiation of the disease $[10,11]$.

We encountered a disease of unknown etiology on a diary farm in Tochigi Prefecture, which presented clinically as urticaria and decreased milk production, and on histopathological examination appeared as lymphocytic to lymphogranulomatous inflammation in multiple organs. The clinical signs and histopathological findings of this disease were similar to those seen in the cases of poisoning mentioned above. Citrus pulp had been fed to the lactating cows on this farm, and the first death occurred 3.5 months after the start of feeding. The outbreak of this disease resolved with the elimination of Citrus pulp from the feed. Here we profile the outbreak of the disease, with an emphasis on the pathologic findings.

\section{MATERIALS AND METHODS}

Clinical history: In March 2002, an idiopathic disease

\footnotetext{
* Correspondence to: Haritani, M., National Institute of Animal Health, 3-1-5 Kannondai, Tsukuba-shi, Ibaraki-ken, 305-0856 Japan.
}

occurred in 7 of 92 lactating Holstein cows, 3 of which died over the course of 7 to 18 days. Table 1 shows the ages, clinical disease courses, and clinical signs of the affected cows, and the items comprising the examination performed. Each of the affected cows was over 3 years old, and gave high milk yields (about $35 \mathrm{~kg}$ daily, with the exception of one that had recently calved). Commercial total mixed ration (TMR) containing at most $18 \%$ citrus pulp had been fed to the herd since the end of November 2001. Sudan grass hay and alfalfa hay were used as additional roughage.

The cow that first developed the disease (cow 1) had a prominent generalized alopecia (particularly over the face) and decreased milk production about 1 week before death. Two days before she died, this cow developed urticaria with hemorrhage on the alopecic areas of the legs, together with sluggish behavior. One day before death she showed hematuria, tar-like feces, and nasal hemorrhage. The next cow to develop the disease (cow 2) had pyrexia, decreased milk production, urticaria with alopecia over the face, legs and udder, and salivation followed by death 9 days after the first appearance of signs. The third cow to die (cow 4) was isolated because of signs of pyrexia, decreased milk production, urticaria, and salivation. She was returned to milking after showing signs of improvement, but then developed nasal hemorrhage and hemafecia, and died 18 days after the onset of signs.

One of the affected cows (cow 3 ) developed pyrexia, decreased milk production, skin lesions, and nasal discharge. She was considered to have a poor prognosis and was euthanatized 6 days after disease onset. The other three cows (cows 5-7) also had alopecia and decreased milk production, but later recovered. In all cases, the skin lesions 
Table 1. Age, consequences, and clinical signs of cows, and laboratory tests applied

\begin{tabular}{|c|c|c|c|c|c|c|c|}
\hline Cow number & 1 & 2 & 3 & 4 & 5 & 6 & 7 \\
\hline Age (years-old) & 5 & 3 & 4 & 4 & 8 & 4 & 4 \\
\hline Consequences & Dead & Dead & Euthanized & Dead & Recovered & Recovered & Recovered \\
\hline \multicolumn{8}{|l|}{ Clinical signs } \\
\hline $\begin{array}{l}\text { Urticaria with alopecia } \\
\text { and/or hemorrhage }\end{array}$ & Yes & Yes & Yes & Yes & Yes & Yes & Yes \\
\hline Milk reduction & Yes & Yes & Yes & Yes & Yes & Yes & Yes \\
\hline Pyrexia & $\mathrm{NT}^{\mathrm{a})}$ & Yes & Yes & Yes & Yes & No & NT \\
\hline Epistaxis & Yes & No & No & Yes & No & No & No \\
\hline Hematuria & Yes & No & No & No & No & No & No \\
\hline Tar-like stool & Yes & No & No & Yes & No & No & No \\
\hline \multicolumn{8}{|l|}{ Laboratory tests } \\
\hline Pathology & Yes & Yes & Yes & No & No & No & No \\
\hline Biochemistry & Yes & Yes & Yes & Yes & Yes & Yes & No \\
\hline Abomasal content analysis & Yes & No & Yes & No & No & No & No \\
\hline Bacteriology & Yes & Yes & Yes & No & No & No & No \\
\hline Virology & No & Yes & Yes & No & No & Yes & No \\
\hline
\end{tabular}

a) NT: Not tested.

developed without distinction between areas of white and black hair.

Hematology and biochemistry: Hematological analysis (red blood cell count, white blood cell count, hematocrit, and differential blood count) and serum chemistry (aspartate aminotransferase, gamma glutamyl transferase, total bilirubin, blood urea nitrogen, creatine kinase, creatinine, amylase, ammonia and hemoglobin) were performed on 6 cows (excluding cow 1) using the blood samples collected when the outbreak of the disease was confirmed. Blood biochemical parameters were determined by dry chemistry technique (Fuji Drychem 5500, Fuji Photo Film, Tokyo, Japan).

The ammonia concentrations of ruminal and abomasal fluid from cows 1 and 3, fluid from the reticulum of cow 3, and used and unused litter were measured by the indophenol method. Gastric fluid samples were collected at necropsy. The mycotoxin levels in the TMR were assayed by ELISA kit (Ridascreen Fast, R-Biopharm, Darmstadt, Germany). The targeted mycotoxins were citrinin, deoxynivalenol, and ochratoxin A. The nitrate-nitrogen concentrations in the feeds were measured using the Japanese official method for the determination of forage nitrate.

Bacteriology and virology: Bacteriological and virological examinations were performed on cows 1-4.

Pathology: Necropsy was conducted on cows 1-3. The collected organs were fixed with $10 \%$ neutral phosphatebuffered formalin. Paraffin sections were prepared by the commonly used procedure, and the sections were stained with hematoxylin and eosin. Prussian blue, Ziehl-Neelsen, phosphotungstic acid hematoxylin stain, toluidine blue, Masson's trichrome stain, Watanabe's method for reticulum, periodic acid-Schiff method and Gram stains were also used as necessary.

In addition, to detect mononuclear cell surface antigens, immunohistochemistry was conducted on paraffin sections of the lesions by the streptavidin-biotin method (Histofine SAB, Nichirei, Tokyo, Japan). As a primary antibody, the anti-CD3 monoclonal antibody (M7254, Dako Japan Co., Kyoto, Japan) for the detection of T-lymphocytes, anti-79a monoclonal antibody (M7051, Dako Japan) for the detection of B-lymphocytes, and anti-CD68 monoclonal antibody (M0718, Dako Japan) for the detection of macrophages were used. For antigen retrieval, the sections were autoclaved in $1 \mathrm{mM}$ disodium ethylenediaminotetraacetate $(\mathrm{pH}$ 8.0) at $120^{\circ} \mathrm{C}$ for $5 \mathrm{~min}$ for the detection of CD3 and CD79a, or incubated in $0.1 \%$ actinase $\mathrm{E}$ at $37^{\circ} \mathrm{C}$ for $20 \mathrm{~min}$ for the detection of CD68. To confirm the reactivity of each antibody, a splenic sample from a normal cow was simultaneously immunostained.

\section{RESULTS}

Hematology and biochemistry: Hematological examination revealed no dramatic changes. In the serum chemistry analyses, the values of glucose (50 to $233 \mathrm{mg} / l$ ), AST (94 to $271 \mathrm{IU} / l)$, GGT (24 to $77 \mathrm{IU} / l)$, BUN (15 to $42.1 \mathrm{mg} / l$ ), CK $(86$ to $>2000 \mathrm{U} / l)$, and creatinine $(0.8$ to $2.1 \mathrm{mg} / l$ ) were high. The ammonia concentrations in the gastric contents were extremely high (ruminal fluid: 71.1 to $72.1 \mathrm{mg}$ ammonia-nitrogen/dL, reticular fluid: $75.2 \mathrm{mg}$ ammonia-nitrogen $/ l$ and abomasal fluid: 22.7 to $37.0 \mathrm{mg}$ ammonia-nitrogen $/ l$ ). These values were several times higher than normal. Although citrinin, deoxynivalenol, and ochratoxin A, which are mycotoxins, were detected in the TMR, their concentrations were low. Some nitrate-nitrogen concentrations in the roughage were high (Sudan grass hay: $1,550 \mathrm{ppm}$, alfalfa hay: 330 ppm and citrus pulp pellets: $11 \mathrm{ppm}$ ), but the concentration in the TMR that was actually fed to the cows were low (55 ppm).

Bacteriology and virology: In a pathogen search, no sig- 
Table 2. Macroscopic and microscopic findings of cows 1-3

\begin{tabular}{|c|c|c|c|}
\hline Cow number & 1 & 2 & 3 \\
\hline \multicolumn{4}{|l|}{ Macroscopic findings } \\
\hline Urticaria with alopecia & Yes & Yes & Yes \\
\hline Hepatomegaly with discoloration & Yes & Yes & Yes \\
\hline Splenomegaly / white pulp enlargement & Yes / Yes & Yes / Yes & No / Yes \\
\hline Renal discoloration / white patches & Yes / Yes & Yes / Yes & Yes / No \\
\hline Hypercardia / epicardial hemorrhage & Yes / Yes & Yes / Yes & Yes / No \\
\hline Abomasal ulceration & Yes & Yes & Yes \\
\hline Vicical hemorrhage & Yes & No & No \\
\hline \multicolumn{4}{|l|}{ Microscopic findings } \\
\hline Skin & $\mathrm{NT}^{\mathrm{a})}$ & LGI $^{\mathrm{b})}\left(\mathrm{E}^{\mathrm{c})}\right)$, Hemorrhage & LGI(E) \\
\hline Liver & Centrilobular necrosis & $\begin{array}{l}\mathrm{LGI}\left(\mathrm{G}^{\mathrm{d})}\right) \text {, } \\
\text { Centrilobular necrosis }\end{array}$ & $\_$e) \\
\hline Spleen & LGI(G) & LGI(G) & LGI(G) \\
\hline Kidney & LGI(G) & LGI(G) & LGI(G) \\
\hline Heart & LGI(G), Hemorrhage & LGI(E) & LGI \\
\hline Lungs & - & Hemorrhage & - \\
\hline Salivary glands & NT & NT & LGI(E) \\
\hline Digestive tract & Hemorrhage & - & - \\
\hline Pancreas & NT & NT & LGI \\
\hline Urinary bladder & Hemorrhage & NT & - \\
\hline Adrenal glands & NT & NT & LGI \\
\hline Mammary glands & NT & NT & LGI \\
\hline Lymph nodes & NT & $\begin{array}{l}\text { LGI(G), } \\
\text { Hemorrhage, } \\
\text { Paracortical hyperplasia }\end{array}$ & $\begin{array}{l}\text { LGI }(G) \text {, } \\
\text { Paracortical hyperplasia }\end{array}$ \\
\hline Trigeminal ganglion & NT & NT & LGI \\
\hline
\end{tabular}

a) NT: Not tested.

b) LGI: Lymphogranulomatous inflammation.

c) (E): With eosinophilic infiltration.

d) $(\mathrm{G})$ : With giant cells.

e) -: No significant lesion.

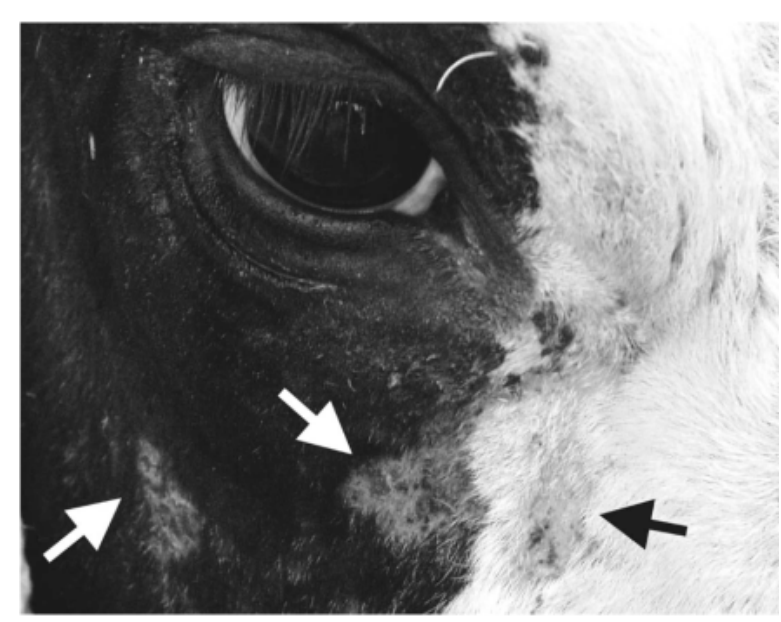

Fig. 1. The face of cow 3. Epilation can be seen in both the black and white-haired skin (arrows) .

nificant pathogens were detected.

Pathology: Table 2 gives a profile of the necropsy findings and histopathological findings in cows 1-3. Observation of multiple alopecia (over the face, legs, udders, and other areas of the body) was common in the three cases (Fig. 1). Cows 1 and 2 had enlarged spleens, with white pulp that

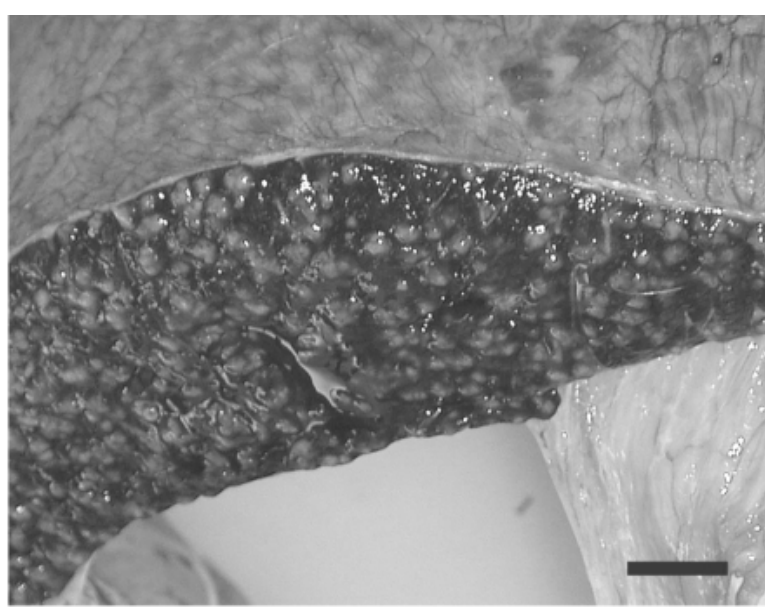

Fig. 2. Cut surface of the spleen of cow 3. Notice marked enlargement of the white pulp. Bar $=1 \mathrm{~cm}$.

was more distinct than normal. The hearts were about double normal size, and ecchymoses were spread all over the epicardium and endocardium. Discoloration or scattered white spots were observed on the surface of the kidneys. When the spots were cut, white streaking reached into the deep renal cortex. The liver was also discolored and 


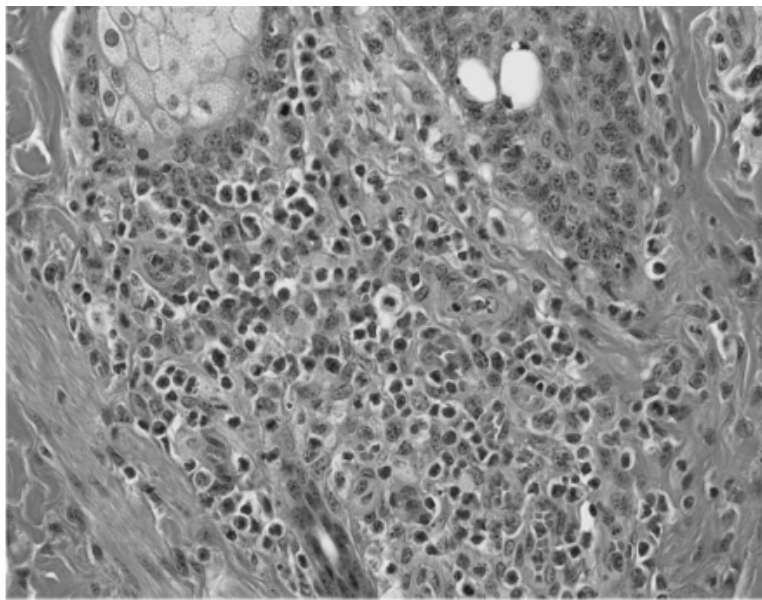

Fig. 3. Cervical skin of cow 3. Lymphocyte, macrophage and eosinophilic infiltration around hair follicule and sebaceous gland. Hematoxylin and eosin (HE) stain, $\times 266$.

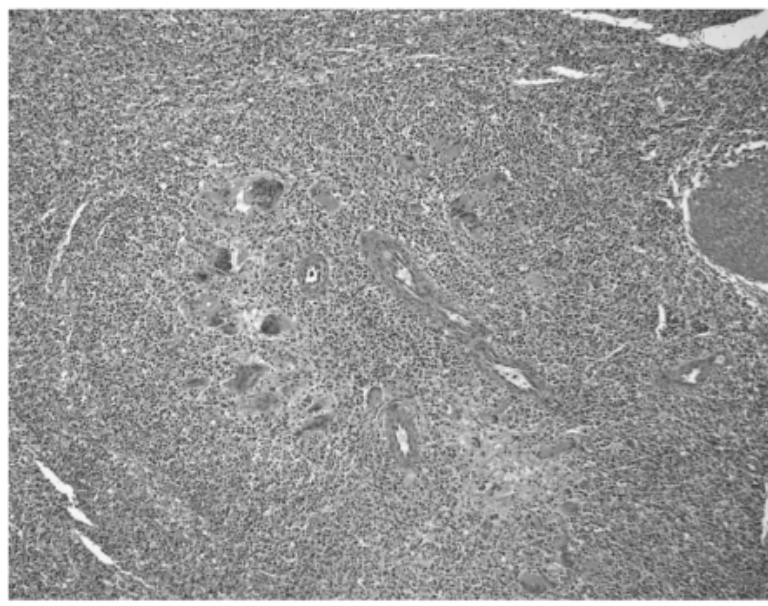

Fig. 5. Spleen of cow 3. The expanded white pulp had an unclear peri arterial lymphatic sheath and lymphatic follicule. HE stain, $\times 66$.

enlarged. The abomasum had bleeding from the mucosa as well as an ulcer. Cow 1 had bleeding from the mucosa of the bladder, soybean-sized to macular bleeding from the serosa of the rumen, greater omentum, and mesentery, punctate hemorrhage from the uterus, and coagulopathy of blood in the heart. Scattered subcutaneous hemorrhages were seen in cow 2. Cow 3, which was euthanized, had an abomasal ulcer, ulceration of the nasal cavity, distinct white pulps of the spleen (Fig. 2), enlargement and discoloration of the liver, adrenal gland and kidneys, and enlarged lymph nodes throughout the body. Although cow 3 and one of the dead cows were pregnant, no lesions were observed in the fetuses.

Histologically, the skin, liver, spleen, kidneys, heart, salivary glands, pancreas, adrenal glands, mammary glands, lymph nodes, and trigeminal ganglia had lymphocytic to

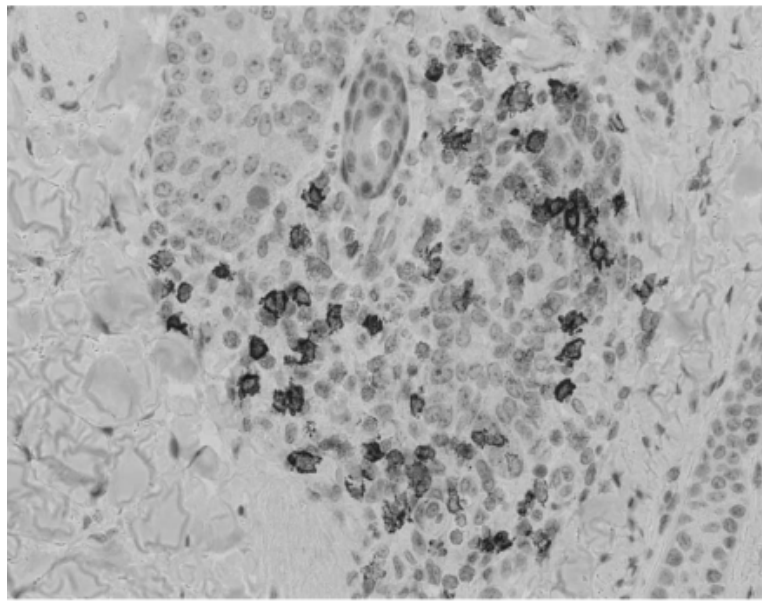

Fig. 4. Cervical skin of cow 3. Immunohistochemical examination showed that most of the infiltrating lymphocytes were positive for CD3. $\times 266$.

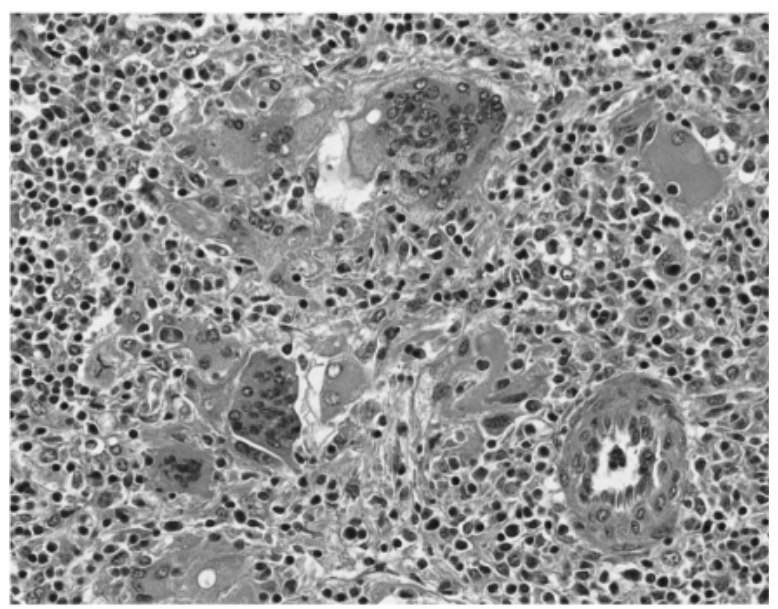

Fig. 6. Spleen of cow 3. Many multinucleated giant cells were observed in the white pulp. HE stain, $\times 266$.

lymphogranulomatous inflammation. Inflammation predominated by infiltration of small lymphocytes was prominent in the heart, pancreas, mammary glands, adrenal glands, and trigeminal ganglia. Granulomatous inflammation with multinucleated giant cells was severe in the spleen and kidneys, and mild to moderate in the liver, heart, lymph nodes and skin. The heart, salivary glands, and skin had eosinophilic infiltration. In addition, mild to very mild infiltration of neutrophils and mast cells was seen in the lesions.

The alopecic areas of skin had mild irregular dermal ridges, mild acanthosis and hyperkeratosis, mild to moderate infiltration of eosinophilic leukocytes, macrophages, and lymphocytes around the dermal vessels and sebaceous glands, and mild hyperplasia of the sebaceous glands of the dermis (Fig. 3). Immunohistochemical examination showed that most of the infiltrating lymphocytes were positive for 


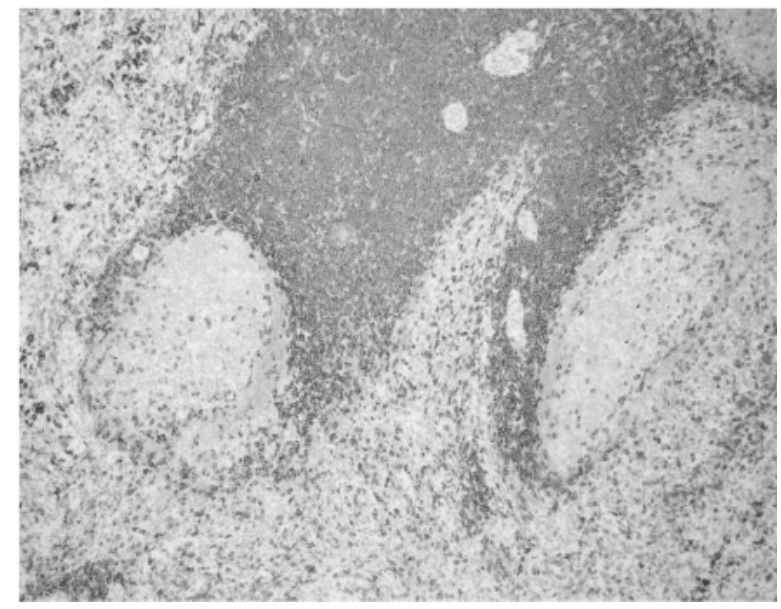

Fig. 7. Spleen taken from a healthy cow. Immunohistochemical examination revealed peri arterial lymphatic sheath composed of $\mathrm{CD} 3$ positive cells. $\times 66$.

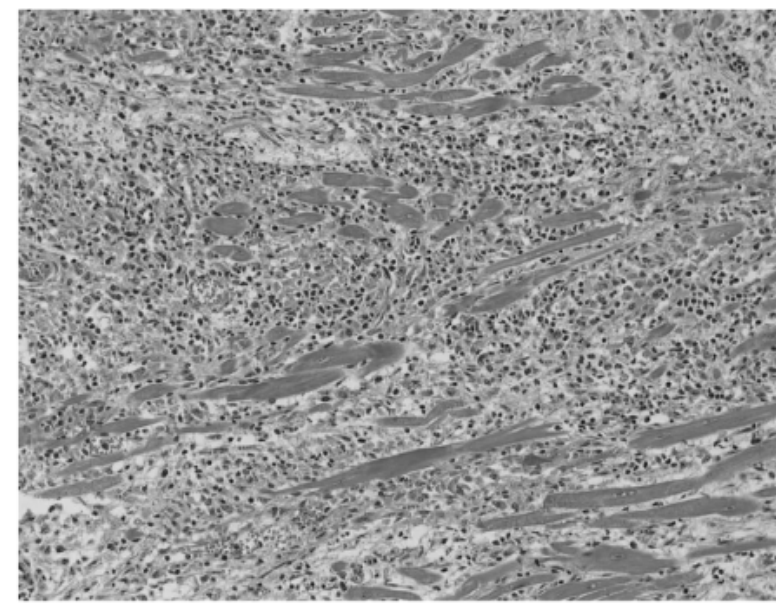

Fig. 9. Myocardium of cow 2. Large infiltrations of lymphocytes and macrophages into the myocardial interstitium. HE stain, $\times 133$.

\section{CD3 (Fig. 4).}

In the spleen, the expansion of white pulp could be observed very clearly at low magnification (Fig. 5). The density of lymphocytes in the splenic white pulp was mildly decreased, and infiltration of numerous multinucleated giant cells was observed in and around the white pulp (Fig. 6). No bacteria was detected in the cytoplasm of the multinucleated giant cells in the acid-fast stained specimens. In the splenic red pulp, areas of hyperemia and moderate yellowish-brown pigmentation, which stained positively with Prussian blue, were observed. Immunohistochemically, the affected cows had an unclear margin between the T-cells and B-cells in the splenic white pulp, compared with healthy cows (Figs. 7, 8). CD3-positive cells were diffusely present (Fig. 8), and a small number of CD79a-positive cells were scattered in the white pulp, but not in the germinal centers. Multinucleated giant cells were positive for CD68.

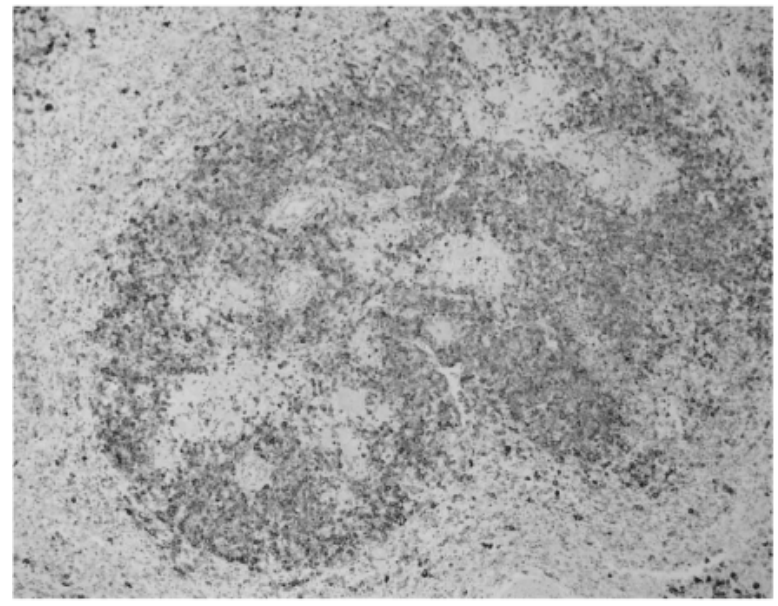

Fig. 8. Spleen of cow 3. Immunohistochemical examination revealed that most of the lymphocytes in the white pulp showed positive for CD3. No giant cells stained. $\times 66$.

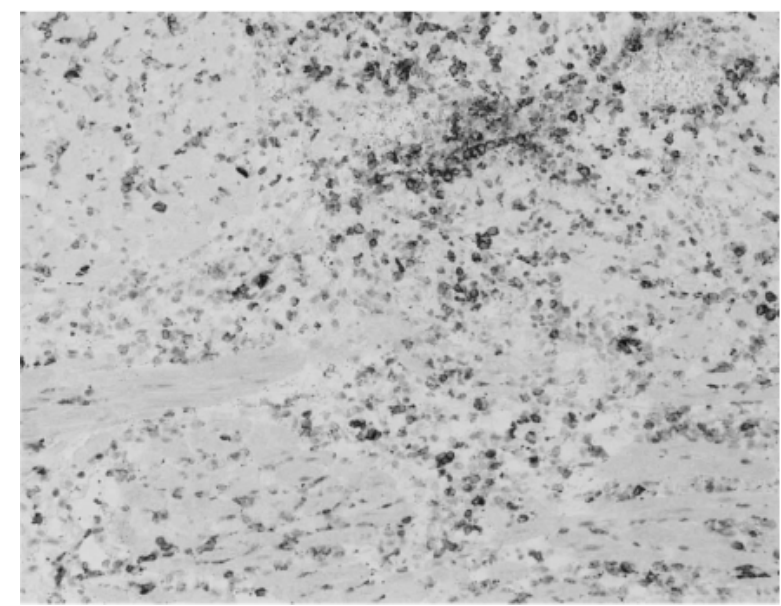

Fig. 10. Myocardium of cow 2. Immunohistochemical examination revealed most of the lymphocytes in the lesion were positive for CD3. $\times 133$.

The three dead cows had large infiltrations of lymphocytes and macrophages into the myocardial interstitium (Fig. 9). Cow 1 had hemorrhage and infiltration of multinucleated giant cells, and cow 2 had mild eosinophilic infiltration. Immunohistochemistry revealed that most of the infiltrating lymphocytes were positive for CD3 (Fig. 10).

Cow 3 had infiltration of lymphocytes and macrophages, with a small number of multinucleated giant cells, in the interstitium of the salivary glands, pancreas, adrenal glands and mammary glands (Fig. 11). Immunohistochemically, most of the infiltrating lymphocytes were positive for CD3, as in the other tissues (Fig. 12).

In cows 1 and 2 the liver showed centrilobular necrosis, and the heart, lungs, trachea, digestive tract wall, urinary bladder, skin, and lymph nodes showed evidence of fresh hemorrhage. In the lymph nodes of cow 3, hyperplasia of the paracortex and histiocytosis of the medullary sinus were 


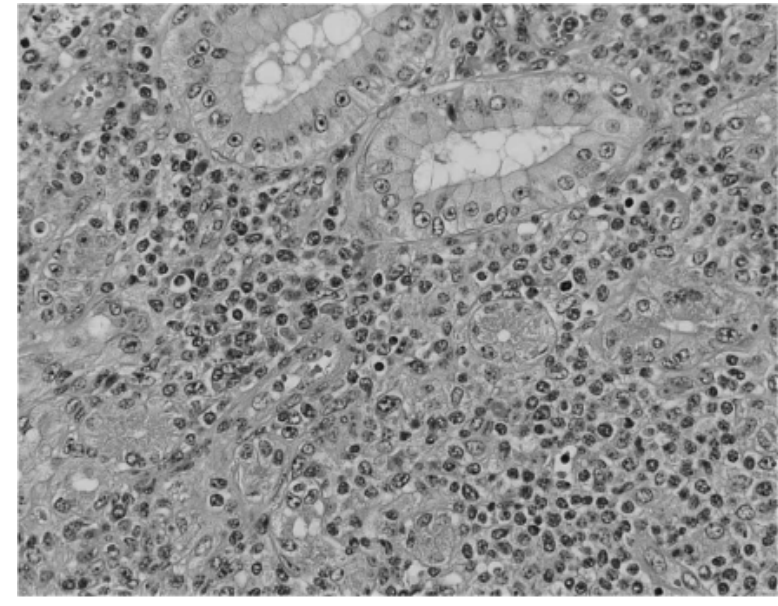

Fig. 11. Submaxillary gland of cow 3 . Severe interstitial lymphatic infiltration. HE stain, $\times 266$.

prominent. Histopathological examination was performed on the fetus of cow 3 , but no lesions were observed.

\section{DISCUSSION}

Pathological examination of three lactating cows that had showed signs of rash and decreased milk production revealed lymphocytic to lymphogranulomatous inflammation of the skin, liver, spleen, kidneys, heart, salivary glands, pancreas, adrenal glands, mammary glands, lymph nodes, and trigeminal ganglia. Lymphocytic infiltrate-predominant inflammation was prominent in the heart, pancreas, mammary glands, adrenal glands and trigeminal ganglia. Granulomatous inflammation with multinucleated giant cells was severe in the spleen and kidneys, and was mild to moderate in the liver, heart, lymph nodes and skin. These tissue lesions and their distributions were most similar to those seen in cases of suspected citrus pulp toxicosis [11] and hairy vetch toxicosis $[2,4,5,7,9,10]$. In DUIB toxicosis [6], the liver, heart, kidneys, and salivary glands have similar lesions to those seen here, but the spleen had only atrophic white pulp or mild hyperplasia of the epithelioid cells. In a disease called 'pruritus, pyrexia and hemorrhagic syndrome' [3], which may be caused by mycotoxin citrinin, generalized lymphogranulomatous inflammation is also observed, but this disease specifically has prominent hemorrhagic changes and relatively mild hyperplasia of the white pulp. However, the four diseases mentioned above should be classified into the same category, because we considered that the slight differences in the lesions observed may have merely reflected differences in the duration of disease at the time of necropsy.

In the case of hairy vetch toxicosis and suspected citrus pulp toxicosis, it has been suggested that a type 4 hypersensitive reaction is involved in the initiation of disease, because the main signs are lymphogranulomatous inflam-

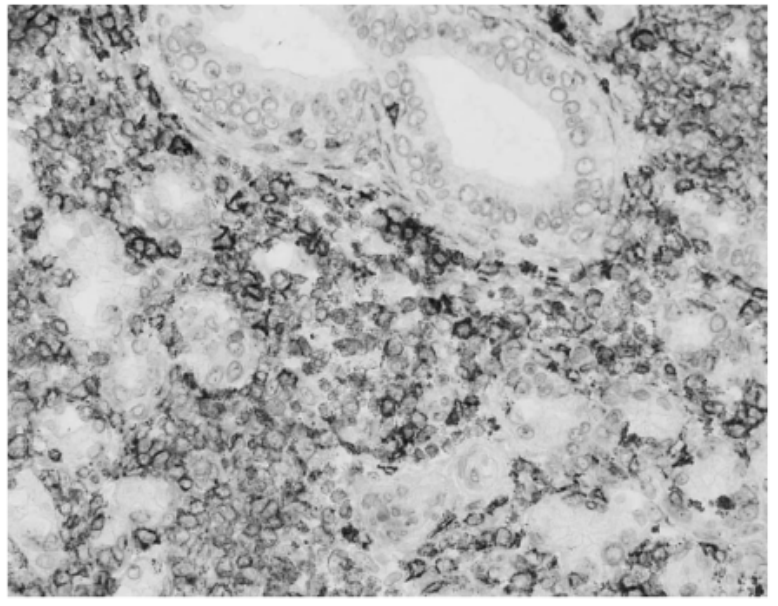

Fig. 12. Submaxillary gland of cow 3. Immunohistochemical examination revealed most of the infiltrated cells were positive for CD3. $\times 266$.

mation $[1,8,10,11]$. A type 4 hypersensitive reaction is caused by a $\mathrm{T}$ lymphocyte response. The immunohistochemical detection of lymphocytes and macrophage markers in our cases revealed a dramatic hyperplasia of CD3-positive $T$ lymphocytes in the $\mathrm{T}$ cell-dependent areas of the spleen and lymph nodes. In addition, we confirmed that most of the lymphocytes infiltrating each organ were $T$ lymphocytes. Our results suggest more clearly than those of the other reports that a type 4 hypersensitive reaction is involved in the development of the lesions. Further investigations of T cell markers such as CD4 and CD8, and of the dynamics of cytokines, will clarify the mechanism of initiation of this disease.

In the present cases, granulomatous inflammation was sometimes associated with multinucleated giant cells. Although the exact mechanisms of the formation and the functional significance of multinucleated giant cells are not determined, particularly interferon- $\gamma$ released by activated $T$ cells is considered to play a pivotal role in monocyte fusion $[1,8]$. The giant cell may be a terminal differentiation stage of the monocyte/macrophage line [1]. In the present case, formation of multinucleated giant cells was most sever in the spleen and kidney. This may mean that these organs have been firstly affected.

It is difficult to identify citrus pulp as a factor involved in the initiation of this disease because citrus pulp is commonly fed to dairy cows without causing problems. However, the clinical course of the disease was similar to that of hairy vetch toxicosis and to that of the suspected citrus pulp toxicosis reported earlier, as in all instances the outbreak of disease was observed in lactating cows over 3 years old, and the disease had a low morbidity rate (8\%) and a high mortality rate $(43 \%)$, as well as the pathological similarities mentioned above $[4,6,10,11]$.

The dairy farmer in question had begun using the TMR containing citrus pulp about 3.5 months before the initiation 
of the disease, and 1 month before the first death, citrus pulp accounted for $18 \%$ of the diet. However, in a suspected outbreak of citrus pulp toxicosis in the United States in 2000 , citrus pulp accounted for only $6 \%$ of the total feed. In that report, the outbreak of disease occurred only in lactating cows, although citrus pulp was fed to both lactating cows and heifers [11]. In our case, citrus pulp was fed to both lactating cows and dry cows, but the amount given to dry cows was very low, and the dry cows had no symptoms.

The farmer stopped feeding citrus pulp to eliminate a possible cause of death. Although another cow died within the next 10 days, no further deaths have occurred since. However, we cannot completely deny the possibility of other causes of this disease, because some of this farmer's cows developed slight alopecia 6 months after the end of the outbreak. Various stresses such as high milk yield, pregnancy, and labor may be involved in the initiation of this disease.

\section{REFERENCES}

1. Barnetson, R., Gawkrodger, D. and Britton, W. 1998. Hypersensitivity-Type IV. pp. 341-352. In: Immunology, 5th ed. (Roitt, I. ed.), Mosby, London.

2. Burroughs, G. W., Neser, J. A., Kellerman, T. S. and Van Niekerk, F. A. 1983. Suspected hybrid vetch (Vicia villosa crossed with Vicia dasycarpa) poisoning of cattle in the Republic of South Africa. J. South Afr. Vet. Assoc. 54: 75-79.

3. Griffiths, B. and Done, S. H. 1991. Citrinin as a possible cause of the pruritus, pyrexia, and hemorrhagic syndrome of cattle.
Vet. Rec. 129: 113-117.

4. Harper, P. A. W., Cook, R. W., Gill, P. A., Fraser, G. C., Badcoe, L. M. and Power, J. M. 1993. Vetch toxicosis in cattle grazing Vicia villosa ssp. dasycarpa and $V$. benghalensis. Aust. Vet. J. 70: 140-144.

5. Johnson, B., Moore, J., Woods, L. W. and Galey, F. D. 1992. Systemic granulomatous disease in cattle in California associated with grazing hairy vetch (Vicia villosa). J. Vet. Diagn. Invest. 4: 360-362.

6. Matsukawa, K., Okada, M. and Kubo, M. 1983. Pathomorphological findings of DUIB (1,1-Diureide isobutene) intoxication cases in dairy cattle. J. Coll. Dairying 10: 197-204.

7. Odriozola, E., Paloma, E., Lopez, T. and Campero, C. 1991. An outbreak of Vicia villosa (hairy vetch) poisoning in grazing Aberdeen Angus bulls in Argentina. Vet. Hum. Toxicol. 33: 278-280

8. Okamoto, H., Mizuno, K. and Horio, T. 2003. Monocytederived multinucleated giant cells and sarcoidosis. J. Dermatol. Sci. 31: 119-128.

9. Panciera, R. J., Johnson, L. and Osburn, B. I. 1966. A disease of cattle grazing hairy vetch pasture. J. Am. Vet. Med. Assoc. 148: 804-808.

10. Panciera, R. J., Mosier, D. A. and Ritchey, J. W. 1992. Hairy vetch (Vicia villosa Roth) poisoning in cattle: update and experimental induction of disease. J. Vet. Diagn. Invest. 4: 318-325.

11. Saunders, G. K., Blodgett, D. J., Hutchins, T. A., Prater, R. M., Robertson, J.L., Friday, P. A. and Scarratt, W. K. 2000. Suspected citrus pulp toxicosis in dairy cattle. J. Vet. Diagn. Invest. 12: 269-271. 